\title{
Reinforcement Effect of PCM Shotcrete Method Using FRP Grid for Tunnel Maintenance
}

\author{
Yukihiro HIGASHI \\ Graduate School of Engineering \\ Nagasaki University \\ Nagasaki City, Japan \\ e-mail: bb52211103@cc.nagasaki-u.ac.jp
}

Bo LI

Graduate School of Engineering

Nagasaki University

Nagasaki City, Japan

e-mail: libo@nagasaki-u.ac.jp

\author{
Yujing JIANG \\ Graduate School of Engineering \\ Nagasaki University \\ Nagasaki City, Japan \\ e-mail: jiang@nagasaki-u.ac.jp
}

\begin{abstract}
The PCM shotcrete method using FRP grid, with the properties of high strength, low weight, high workability, strong resistance to corrosion, and little influence on the existing structures, has been used in tunnel maintenance to repair the damaged lining of some aged tunnels. However, the construction cases are still few, and the design routine of this method based on quantitative evaluation on the reinforcement effect has not been established. In this study, we estimated the shear bond strength and the shear stiffness of a typical FRP grid by direct shear test. Those parameters were input into the numerical tunnel model to quantitatively estimate the displacement control effect of the FRP-PCM method. The experiment and numerical simulation results show that the FRP-PCM method has good reinforcement effect on tunnel lining.
\end{abstract}

Keywords-Tunne lining; Reinforcement method; Numerical simulation; FRP grid

\section{INTRODUCTION}

In recent years, many tunnels that have been in service for several decades have suffered damages in different degrees. In such tunnels, convergence continuously grows with the deterioration of lining concrete and surrounding rock mass, inducing the damages like cracking and spalling. To maintain the operational function of tunnels, a number of reinforcement methods are used to improve the integrity of lining concrete. Typical ones include grouting, steel board bonding method, and carbon fiber sheet bonding method etc ${ }^{1)}$. Recently, Polymer Cement Mortar (PCM) shotcrete method using the FRP (Fiber Reinforcement Plastics) grid (FRP-PCM method) was proposed.

The FRP grid has high strength, low weight, high workability, strong resistance to corrosion, and little influence on the existing structures. The operation and maintenance of FRP-PCM method is relatively easy, which also adapts well to the environment of construction site. The strength property and the deformation characteristics of FRP-PCM have been estimated through bending test and bonding test ${ }^{2), 3)}$. However, the construction case of applying FRP-PCM method to tunnel lining is still few, and the evaluation approach of its reinforcement effect has not been established.

In this study, FRP-PCM test pieces combining PCM and lining concrete using FRP grid were manufactured (see Fig. 1). Direct shear tests were conducted on these test pieces to estimate the shear bond strength and shear stiffness of the FRP grid.

In the next, the values of the shear bond strength and the shear stiffness of FRP grid obtained from laboratory test were input into a tunnel simulation model. The tunnel deformation was simulated taking into account the influences of the ground strength ratio and the cavities in the back of the lining. By doing so, this study aims at establishing a routine for applying FRP-PCM method for the aged tunnels.

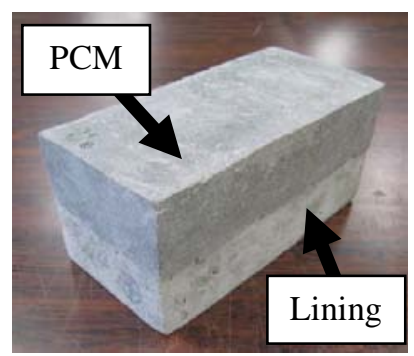

(a) FRP-PCM test piece

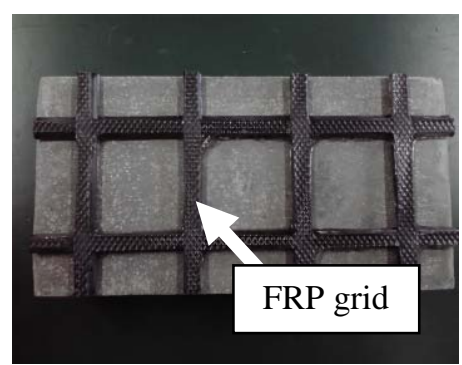

(b) FPR grid installation condition
Figure.1 View of the test piece

\section{ESTIMATION OF THE PROPERTIES OF FRP GRID BY DIRECT SHEAR TEST}

The strength and deformation properties of the FRP grid are usually evaluated by the bending test and the bonding test. However, the shear bond characteristics of FRP grid with

Sponsor: Science meeting of FRP grid method 
lining concrete are not clarified. At here, direct shear test was conducted to estimate the shear bond strength and the shear stiffness of FRP grid.

\section{A. Outline of the shear bond strength test}

Firstly, a concrete test piece representing the lining concrete was manufacture with a size of $50 \mathrm{~mm}$ in height, $100 \mathrm{~mm}$ in width and $200 \mathrm{~mm}$ in length by using a metallic mold (curing period: 14 days). The FRP grid was then affixed on the surface of the concrete block. After that, PCM was poured into the mold to fix the FRP grid between the PCM block and the concrete block. The PCM block has the same size with the concrete block with a curing period of 14 days. One example of the test piece is shown in Fig. 1.

Constant normal load shear test was conducted with normal stresses of $1 \mathrm{MPa}, 2 \mathrm{MPa}$ and $3 \mathrm{MPa}$, respectively, and with shearing speed of $0.5 \mathrm{~mm} / \mathrm{min}^{4)}$. The test case is shown in TABLE. 1. In this test, we used three kinds of grid (CR4, CR6 and CR8) with different cross-sectional areas.

\section{B. Test results}

The result of direct shear bond strength test that used CR4 is shown Fig. 2 as an example. In the test, we used 2-3 test pieces were used for one case in consideration of the difference in the quality of the test pieces. Target strength of the shear bond strength is $2.0 \mathrm{MPa}$ which satisfies the requirement for application on tunnel lining in practices.

As shown in Fig. 2, the maximum shear stress is about 2.4 $\mathrm{MPa}$ when the normal stress is $1 \mathrm{MPa}$, and becomes $2.9 \mathrm{MPa}$ when the normal stress is $2 \mathrm{MPa}$. These values are larger than the target strength of $2.0 \mathrm{MPa}$, which is adequate for engineering practices. The shear stiffness of the bonding surface is calculated by the following equation.

$$
\Delta \tau=k_{s} \cdot \Delta u
$$

Where $\Delta \tau$ is the shear stress increment, $\Delta u$ is the shear displacement increment, $k_{s}$ is the shear stiffness.

The shear stiffness of the bond surface for each grid obtained from direct shear test is shown in TABLE. 2. The shear stiffness of the bond surface increases, as the crosssectional area of the grid rises (i.e. CR4 to CR8).

Moreover, two parameters $c$ and $\varphi$, representing the bond strength were calculated from the result of the shear bond strength test of three kinds of grids, as shown in Fig. 3. The average values of all kinds of grids at each normal stress were used in the calculation, therefore, the parameters obtained from Fig. 3 represent the mean property of all grids ${ }^{5)}$.

\section{MODELING AND VALIDATION OF REINFORCEMENT METHOD}

In the numerical investigations in the past, when inner reinforcement method such as FRP-PCM method and carbon fiber sheet bonding method was modeled, the isotropic elastic medium (Shell element) that could represent the thickness of
TABLE. 1 Test case

\begin{tabular}{cccc}
\hline FRP grid & CR4 & CR6 & CR8 \\
\hline \multirow{2}{*}{ Nomal stress } & $1 \mathrm{MPa}$ & $2 \mathrm{MPa}$ & $1 \mathrm{MPa}$ \\
& $2 \mathrm{MPa}$ & $3 \mathrm{MPa}$ & $3 \mathrm{MPa}$ \\
\hline
\end{tabular}

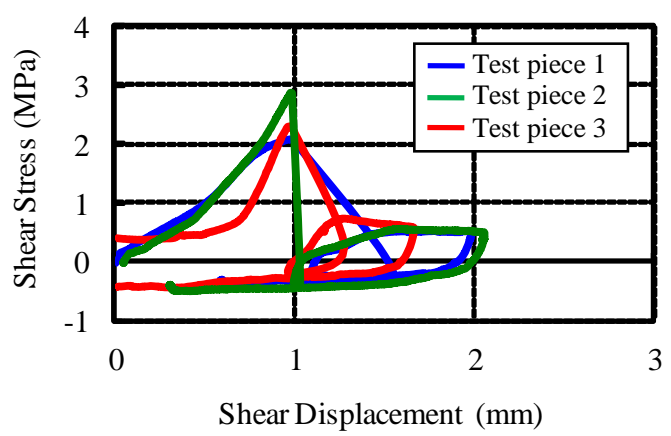

(a) Normal Stress: $1 \mathrm{MPa}$

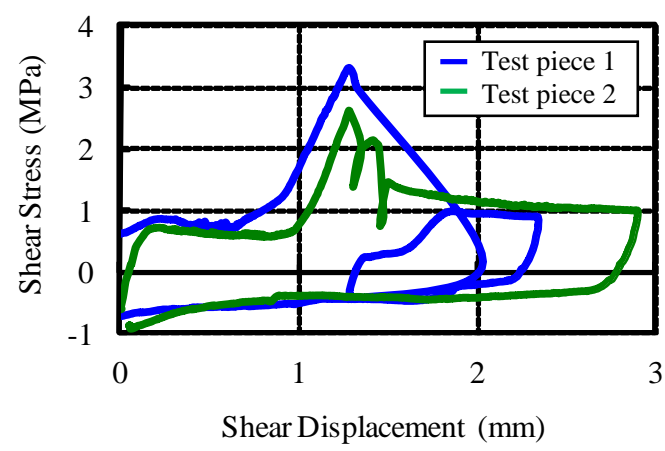

(b) Normal Stress: $2 \mathrm{MPa}$

Figure.2 Result of shear bond strength test (CR4)

TABLE.2 Shear bond stiffness

\begin{tabular}{|c|c|}
\hline Grid & $\begin{array}{c}\text { Mean } \\
(\mathrm{MPa} / \mathrm{mm})\end{array}$ \\
\hline CR4 & 5.298 \\
\hline CR6 & 6.394 \\
\hline CR8 & 13.369 \\
\hline
\end{tabular}

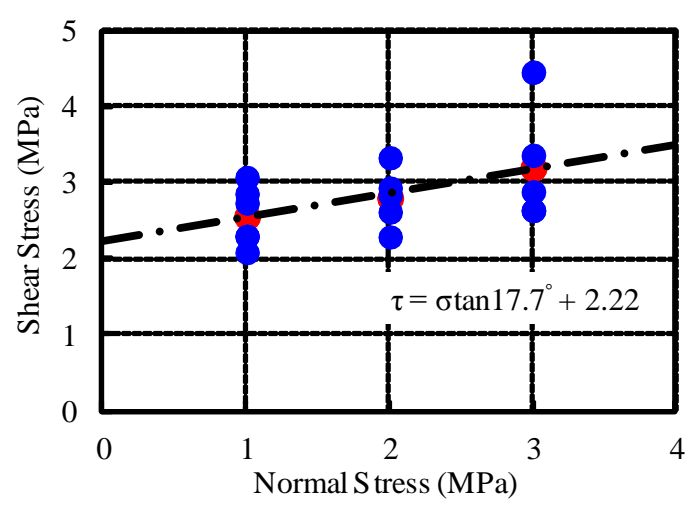

Figure.3 Calculated result of shear bond strength

the material in elastic phase was usually used ${ }^{6), 7)}$. However, the destruction of the bonding area or material can be aroused by 

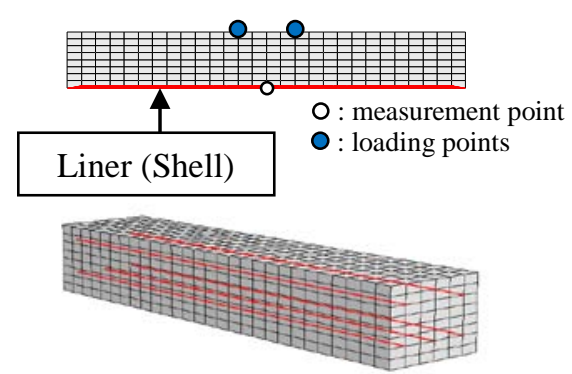

- : Steel Bar

Figure. 4 Outline of numerical model
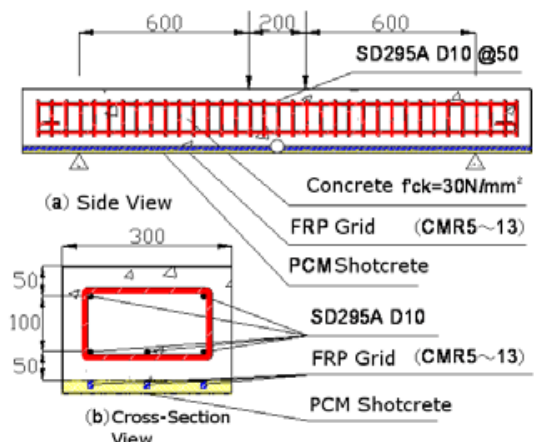

Figure.5 Outline of test piece

TABLE.3 Properties of materials

\begin{tabular}{cccc}
\hline Material & $\begin{array}{c}\sigma_{c} \\
(\mathrm{MPa})\end{array}$ & $\begin{array}{c}E \\
(\mathrm{MPa})\end{array}$ & $\begin{array}{c}k_{\mathrm{s}} \\
(\mathrm{MPa} / \mathrm{m})\end{array}$ \\
\hline Concrete & 43.6 & $3.28 \times 10^{4}$ & - \\
Steel bar & - & $2.10 \times 10^{5}$ & - \\
FRP-grid (CR6) & - & $2.00 \times 10^{5}$ & $11.64 \times 10^{3}$ \\
PCM & 36.3 & $2.70 \times 10^{5}$ & \\
\hline
\end{tabular}

the deformation of the tunnel. The reinforcement effect of inner reinforcement method depends on the strength and the stiffness of the bonding area. Therefore, in this study, we used the structural element (Liner element) which takes account of the shear strength and the deformation stiffness on the bonding area. To verify the model adopting the liner element, a reproduction simulation was conducted based on the result of the bend test carried out by the past researches ${ }^{6}$. The outline of the numerical model and the test pieces are shown in Fig. 4 and Fig.5, respectively, and the properties of material are shown in TABLE.3. Loading was applied at two points which are located at the left and right sides $100 \mathrm{~mm}$ apart from the topcenter of the beam, and the measurement point was located at the bottom-center of the beam. The models were constructed by using the finite difference method (code: FLAC ${ }^{3 \mathrm{D}}$ ), using shell element (case 1) and liner element (case 2) respectively.

The comparison between the results of the reproduction simulation and the test is shown in Fig.6. The case 1 shows elastic deformation since the shell element is a perfectly elastic body, and the effect of reinforcement is overestimated. On the other hand, in case 2, since the liner element could take into account the stiffness, the bonding strength and the destruction on the bonding are, the simulation results agree well with the

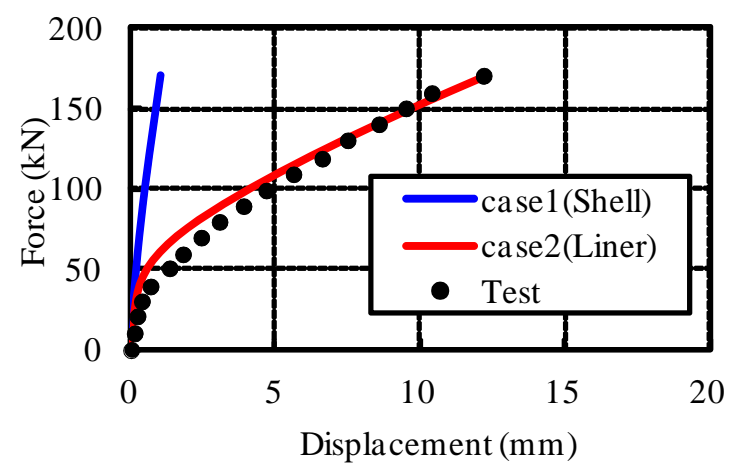

Figure.6 Comparison between result of reproduction simulation and test

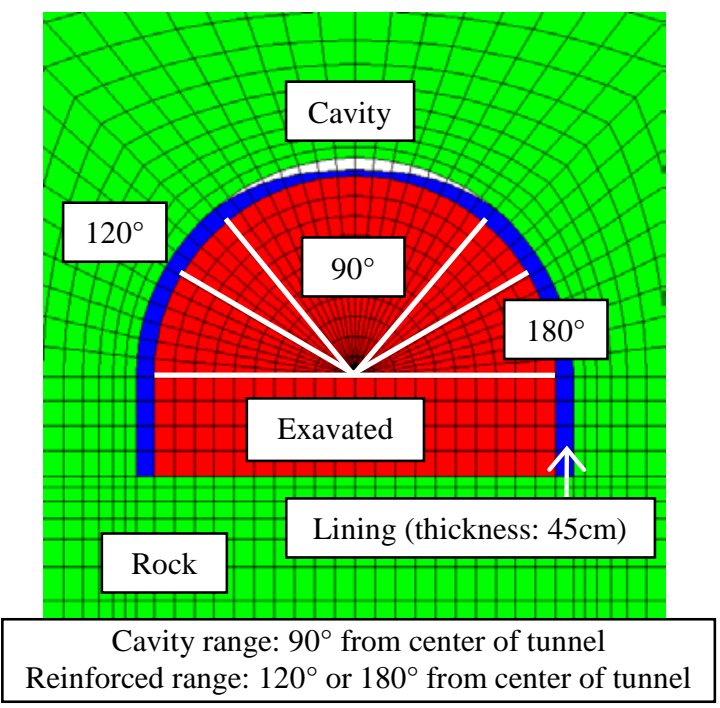

Figure.7 Outline of the numerical model

TABLE.4 Properties of materials

\begin{tabular}{ccc}
\hline Property & Rock & Lining \\
\hline E (MPa) & 1000 & 28000 \\
$v$ & 0.3 & 0.2 \\
c (MPa) & 0.8 & 5.9 \\
$\varphi($ deg) & 30 & 40 \\
$t(\mathrm{MPa})$ & 0.12 & 0.59 \\
\hline
\end{tabular}

TABLE.5 Properties of Reinforcement

\begin{tabular}{ccccc}
\hline Material & $E(\mathrm{MPa})$ & $\varphi_{s}(\mathrm{deg})$ & $c_{s}(\mathrm{MPa})$ & $k_{s}(\mathrm{MPa} / \mathrm{m})$ \\
\hline CR4 & 100000 & 17.7 & 2.22 & $5.30 \times 10^{3}$ \\
PCM & 26000 & & & \\
\hline
\end{tabular}

test results. Therefore, the model of case 2 has better performance in simulating the behavior of reinforcement.

\section{MODELING AND VALIDATION OF REINFORCEMENT METHOD}

\section{A. Outline of numerical model}

Most tunnels reinforced by FRP-PCM method are constructed by conventional construction method. It is reported 


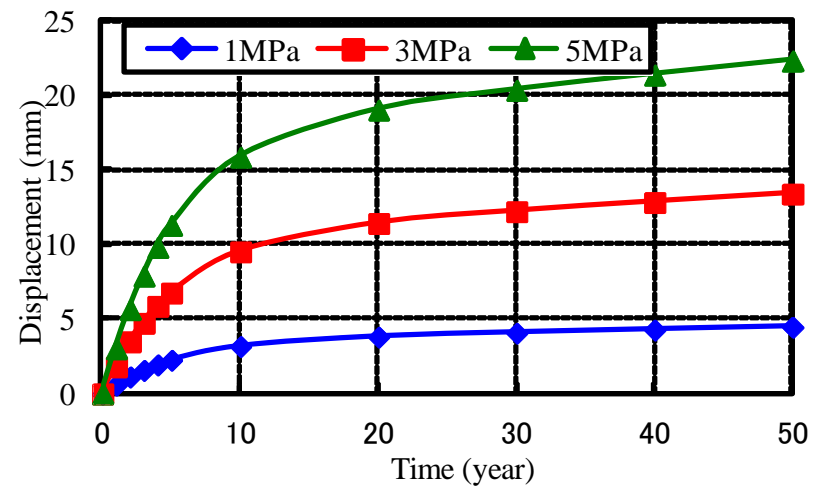

Figure.8 The deformation behavior of the rock

TABLE.6 Simulation cases

\begin{tabular}{|c|c|c|c|}
\hline case & Reinforcement method & timing & area \\
\hline case 1 & None & - & - \\
\hline case2 & Back-fill and FRP-PCM & $\begin{array}{c}3 \text { years } \\
\text { later }\end{array}$ & $120^{\circ}$ \\
\hline case3 & Back-fill and FRP-PCM & $\begin{array}{c}3 \text { years } \\
\text { later }\end{array}$ & $\begin{array}{l}\text { upper half } \\
\left(180^{\circ}\right)\end{array}$ \\
\hline case 4 & Back-fill only & $\begin{array}{c}3 \text { years } \\
\text { later }\end{array}$ & - \\
\hline case 5 & Back-fill and FRP-PCM & $\begin{array}{c}5 \text { years } \\
\text { later }\end{array}$ & $120^{\circ}$ \\
\hline case6 & Back-fill and FRP-PCM & $\begin{array}{c}5 \text { years } \\
\text { later }\end{array}$ & $\begin{array}{l}\text { upper half } \\
\left(180^{\circ}\right)\end{array}$ \\
\hline case7 & Back-fill only & $\begin{array}{c}5 \text { years } \\
\text { later }\end{array}$ & - \\
\hline
\end{tabular}

that in some damaged tunnels, cavities exist in the back of lining usually at the crown through field investigation. Therefore, in this study, numerical model of tunnel was built up taking into account the existence of cavity in the back of lining for the tunnel constructed by the conventional construction method, in order to evaluate the reinforcement effect of FRP-PCM method in aged tunnels.

The outline of numerical model is shown in Fig. 7, and the properties of rock mass, lining concrete and reinforcement materials are shown in TABLE. 4 and 5, respectively. In the numerical simulation, CR4 that has the smallest cross-sectional area was used. The surrounding rock was modeled by viscoelastic-plastic model, the side and the bottom boundaries were set to be roller support, and the overburden load was applied on the top. Moreover, width of the model was set to 3D from the excavated surface in consideration of the influence of excavation (D: the excavation diameter, about $10 \mathrm{~m}$ ), and the thickness of lining concrete at crown was set to $15 \mathrm{~cm}$, for the wall was set to $45 \mathrm{~cm}$. The natural ground strength ratio $(\mathrm{Srp})$ is set to 0.5 .

To understand the deformation behavior of the surrounding rock of the tunnel, overburden stresses $(1,3,5 \mathrm{MPa})$ were applied at the top of a model constituted by pure rock without cavity and excavation (size: $10 \mathrm{~cm}$ in height $\times 5 \mathrm{~cm}$ in width), and the creep simulation was executed. The deformation

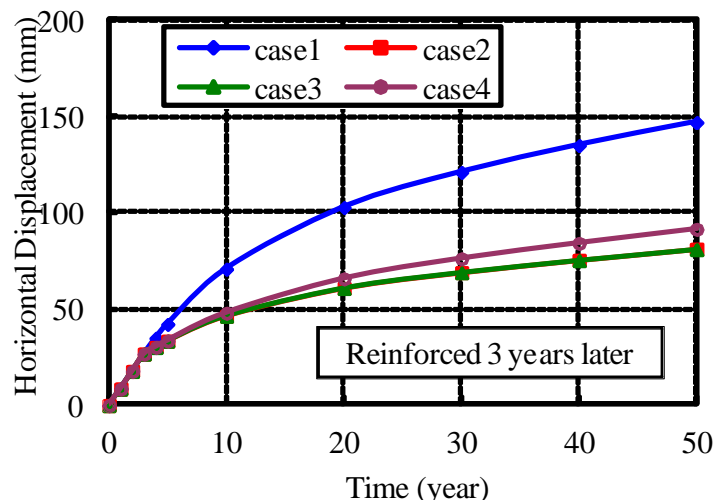

Figure.9 Comparison of horizontal displacement (Reinforced 3 years later)

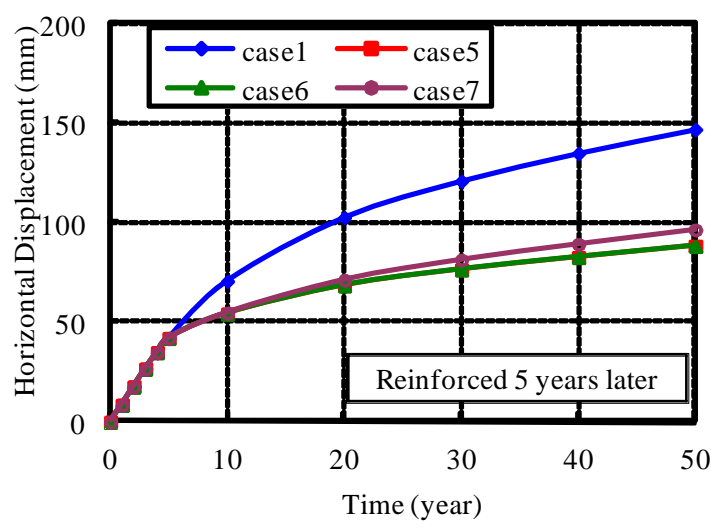

Figure.10 Comparison of horizontal displacement (Reinforced 5 years later)

behavior of the rock model is shown in Fig.8. One can see that the displacement increases fast in the first several years, and then trends to a lower increasing ratio, gradually becoming steady. As a result, the reinforcement times by using FRP-PCM method in later simulation were set to 3 years and 5 years after the starting use of the tunnel, as shown in TABLE. 6. Moreover, the range of the back cavity was set to $90^{\circ}$ from the center of the tunnel based on past investigation results, and the reinforcement range was set to two patterns: $120^{\circ}$ from the center of the tunnel and the upper half of the tunnel as shown in Fig. 7.

\section{Simulation results and discussions}

The comparison of horizontal displacements at S.L. (Spring Line) of cases 2-4 is shown in Fig. 9, and the comparison of horizontal displacements at S.L. of case $5 \sim 7$ is shown in Fig. 10.

As illustrated in Fig. 9 and Fig. 10, remarkable displacement control effect is obtained by back-filling the back cavity. The FRP-PCM method, applied together with back-fill could restrict more displacement. Comparing Fig. 9 with Fig. 10 , it shows that cases 2-4 have smaller displacement than that of the cases 5-7 indicating that lager displacement control effect could be achieved when the enforcement is applied in an earlier stage. 
Comparing case 2 with case 3 in Fig. 9, and case 5 with case 6 in Fig. 10 with different reinforcement ranges, it shows that, despite the reinforcement time (3 years or 5 years later), the cases with different reinforcement ranges have almost coincident displacement. Therefore, enough displacement control effect could be achieved by applying the reinforcement in a relatively narrow range, which could help decrease the construction cost.

\section{CONCLUSION}

In this study, the shear behaviour of FRP-PCM reinforcement was estimated by conducting direct shear tests on the test pieces constituted by lining concrete, FRP grid and PCM. The shear strength and the shear stiffness of a typical FRP grid were calculated. These parameters corresponding to the shear behaviour of FRP-PCM obtained from the tests were input into a tunnel numerical model, which could predict the deformation of tunnel in a long period (i.e. 50 years). The displacement control effect by applying FRP-PCM method was estimated by numerical simulation, and some results are shown below.

(1) The bonding shear strength of FRP grid was obtained through direct shear test. The test results show that all of the bonding shear strength of different kinds of FRP grids exceeds 2.0 MPa, which satisfies the shear strength requirement of FRP grid in engineering practice.

(2) Simulation of bending test on reinforced concrete beam shows that the liner element, which could take into account the bonding strength and bonding stiffness, performs better than the commonly used shell element, when simulating the reinforcement materials.

(3) Remarkable reinforcement effect could be achieved by applying back-fill method together with FRP-PCM method, especially in an earlier stage after a tunnel is put into service (e.g. after 3years). The numerical simulation also shows that coincident reinforcement effect could be achieved by applying the reinforcement in a narrower range (e.g. large enough to cover the back cavity) than the whole upper half of a tunnel.
The aforementioned test and simulation results have shown that the FRP-PCM method has high performance in the reinforcement of tunnel lining. In the future, more sophisticated numerical model taking into account the stiffness degradation due to the aging of lining concrete will be constructed. A rational design routine of applying FRP-PCM method to tunnel lining reinforcement will be proposed by conducting more numerical simulations and more field application.

\section{ACKNOWLEDGMENT}

This study is granted by the science meeting of FRP grid method.

\section{REFERENCES}

[1] Y. Higashi, Y. Jiang, Y. Tanabashi, S. Sugimoto: An analytical evaluation of deformation prediction of tunnel by considering time dependability and the effect of various reinforcing method, Abstructs of the western branch of the Japan Society of Civil Engineering resurch conference, pp.535-536, 2008.

[2] S. Nakamura K. Yamaguchi, Amiruddin A. Arwin, K. Taniguchi: Effect of bending reinforcement of RC beam using CFRP grid by contacted arrangement two layers by PCM shotcrete method, Annual proceedings of concrete engineering, Vol.31, No.2, pp.1429-1434, 2009.

[3] H. Watanabe, S.Hino, K.Yamaguchi, Amiruddin A. Arwin: Experimental research of bond strength in CFRP grid contacted two layers, Annual proceedings of concrete engineering, Vol.31, No.2, pp.1411-1416, 2009..

[4] Y. Jiang, M.Nakagawa, T.Ezaki: Quantitative evaluation of mechanical properties of the natural rock joints for analyzing behavior of structures in discontinuous rock masses, Proceedings of Civil engineering, III -47, No.624/pp.231-243, and 1999.

[5] The Japanese Geotechnical Society: Soil test - basis and guidance (the first time revised edition), 2001.

[6] S.Okuma, Y.Higashi, Y. Tanabashi, Y. Jiang: Evaluation of effect of tunnel lining reinforcement to use FRP grid, the 45th geotechnical engineering research symposium, and pp.1343-1344,2010.

[7] Y. Higashi et al: Analytical examination in various effects of reinforcement method to displacement of road tunnel, Proceedings of the Symposium on Underground Space, Vol.15, pp.177-182, 2010. 